\title{
FEATURES OF COPING-BEHAVIOR OF STUDENTS \\ WITH VARIOUS LEVEL OF HARDINESS \\ IN THE PERIOD OF THE SESSION
}

\section{Mannapova Kateryna ${ }^{1}$}

DOI: https://doi.org/10.30525/978-9934-571-78-7_46

Abstract.The article deals with the problem of the influence of students' hardiness on the choice of their coping strategies during the session and inter-sessional period. The paper contains an analysis of recent researches and publications within the framework of the main psychological approaches and scientific schools, analyzes current theoretical approaches to the definition of the essence of the problem, the probable effects of influencing the level of hardiness on the strategy of overcoming. There are describedthe main components and preconditions for the development of hardiness. It is noted that the concept of «hardiness» reflects the psychological vitality and increased human efficacy, and is an indicator of its mental health.It is noted that hardiness prevents acute reaction to a stressful situation and it is the main personal component that reduces the influence of stress factors. It is also pointed out that studying process becomes more and more stressful for students, forcing to mobilize all internal resources. Most scholars see overcoming as ever-changing cognitive and behavioral efforts and focusing on managing specific external and internal requirements that are judged from the matching the resources of the individualpoint of view. The probability of the development of psychological stress depends on the personality characteristics that determine the resistance to stress; it is the hardinessthat can be called such a personality peculiarity. Although there are a lot of studies of life-sustainability and hardiness, the identification of coping strategies and mechanisms for protecting students, has well as empirical data on the impact of the level of hardiness on the formation and implementation of coping behavior of the individual is not enough. This led to the goal of our article: the study of the impact of the level of hardiness on the student's coping behavior during the stress period (session period), as

\footnotetext{
${ }^{1}$ Candidate of Psychological Sciences, Associate Professor, Kharkiv National University of Internal Affairs, Ukraine 
well as during the period of relative resting (inter sessional period). There was carried out an analysis among students and the features of coping behavior were determined depending on the level of hardiness. While researching of the impact of the level of hardiness on the coping behavior of students during the session period, the relationship between types of stress management and hardiness indicators was identified - a direct connection between hardiness and distancing, self-control, acceptance responsibility, positive revaluation and planning of problem solving, as well as feedback as the link between hardiness and confrontation, search for social support and avoidance.In order to compare the shift of indicators, a quantitative analysis which allows us to establish not only the direction of change, but also its severity,was conducted. For students with a low level of lifesustainability or hardiness in a state of rest, typical strategies are aimed at re-evaluation the situation, and it is focused on the problem, while in a situation of immediate stress - coping, aimed at removing emotional stress. Students with high indicators of hardiness prefer adaptive variants of cognitive, behavioral and emotional coping strategies of behavior in a state of rest, and in a stressful situation.

\section{Introduction}

Modern life in all spheres of human life and society as a whole puts forward new, previously unknown requirements. Education of the XXI century is education for a person. Its core is a developing, cultural and creative dominant, education of a responsible person who is capable of self-education and self-development, is able to think critically, process various information, uses acquired knowledge and skills for creative problem-solving, seeks to change his or her life and the whole life of the country to better.This is the time of transition to a high-tech information society, in which the quality of human potential, the level of education and culture of the entire population is becoming crucial to the country's economic and social progress. The integration and globalization of the social, economic and cultural processes taking place in the world, the prospects for the development of the Ukrainian state over the next two decades require a profound renewal of the education system, predetermining its pro-active character.

Increasingly, the teaching process is becoming stressful for students, forcing them to mobilize all internal resources. The study of the peculiarities of overcoming difficult life situations by students - the learning process, the 
change of place of residence, the sessional period - have always been largely represented among psychological research. This situation is persisting today. This is explained by the fact that the educational process is constantly getting complicated, the structure of the educational system and its institutions are getting changed, the transition from the principle of «education for life» to the principle of «education throughout life» is changing.

Different life situations faced by people in their life path, cause adaptive activity, stimulating the physical and mental resources of the organism. Mental level of adaptation rather than physiological one is the most sensitive indicator of stress. Due to an emotional-stressful state of the organism qualifies as a result of perceiving the situation as inappropriate, negative, with the simultaneous impossibility of its avoidance. Physiological manifestations for different types of stress are the same type, while the set of psychological (emotional, behavioral) manifestations under psychological stress is much more diverse.

Phenomenology, reflecting various aspects of personal potential, in different approaches in foreign and domestic psychology was denoted by such concepts as will, power, inner support, locus of control, orientation to action, will to meaning, and others. The most complete, in terms of D. A. Leontiev, this concept in foreign psychology corresponds to the concept of «hardiness» - «viability», introduced by S. Maddi. Vitality is a key personal variable that mediates the influence of stress factors on somatic and mental health, as well as on the success of personality [7, p. 4].

Although there are many studies of hardiness, the identification of coping strategies and mechanisms for protecting students, along with that, empirical data on the impact of the level of viability on the formation and implementation of coping behavior of the individual is not enough. This led to the goal of our article: the study of the impact of the level of hardiness on the student's coping behavior during the stress period (session period), as well as during the period of relative rest (inter sessional period).

\section{Tasks:}

1. To identify the features of coping behavior, depending on the level of students' hardiness during the session;

2. To carry out a correlation analysis and identify the impact of hardiness on overcoming students strategies during the session;

3. To identify the direction of change in the doping strategies of students with different levels of hardiness during the session and inter-sessional period. 


\section{Analysis of research and publications}

The main reason for the study of this topic by various authors is a qualitative change in the way of life: the contradiction and in stability of the social situation, an increase in the speed of technological progress and the accumulation of information, noted by almost all researchers (G.M. Andreev, A.G. Asmolov, I. Kalaykov, M.V. Romm, G.U. Soldatova, T.G. Stefanenko, A.V. Sukharev, A. Toffler, etc.) - which leads to an increase in the number of people who are notable to control these changes (informational neurosis I. Kalaykov, «futuroshock syndrome», or shock out of changes - A. Toffler), that is, notable to adapt, particularly psychologically, to the uncertainty and instability of modern society.

The problem of overcoming of stressand critical situations by the personality is investigated by scientists in various fields of knowledge: biology, medicine, psychophysiology, psychology - and is currently one of the most urgent in science. In this relation, the study of psychological methods of overcoming as a factor of successful adaptation of man in the modern world becomes a special significance (L.I. Antsiferova, F.B. Berezin, V.O. Bodrov, V.P. Kaznacheyev, A.R. Kudashev, F. Meerson, A.O. Rean, M.S. Yanitsky, etc.). The research notes that unpredictability and uncertaintyhave the most stressful effects on the psychophysical and functional state of the person, which are the main characteristic of stress situations.

Foreign researchers such as J. Adam, F. Alexander, J. Amirkhan, G. Basovich, G. Weylant, R. Lazarus, E. Locke, D. Mechanik, S. Peterson, M. Seligman, H. Selye, N. Scotch, M. Taylor, C. Eldwin and others were studying the process of appearing of stress reactions, methods oftheir prevention and correction of personality behavior in stressful situations.

In the domestic psychology, the study of stress relief was carried out from the standpoint of a person-oriented approach (V.O. Ganzen, L.P. Grimak, E.P. Ilyin, L. Kitaev-Smyk, G.B. Leonov, B.F. Lomov, S.K. Nartova-Bochaver, B.D. Nebylitsyn, K.V. Sudakov, S.S. Chshmarityan, M.G. Yaroshevsky etc.). Scientists have identified and studied the internal subjective conditions that affect the stability of a human to mental stress: the significance of events for the individual (L.I. Ermolaev, M.D. Levitov, Yu.E. Sosnovikov), subjective assessment of the personality of the situation (M.I. Nayenko, Yu.B. Nekrasova, T.A. Nemchin), individual-typological peculiarities of personality (M.I. Dyachenko, V.L. Maryshchuk, R. Moos, K.K. Platonov, V.O. Ponomarenko, V.M. Rusalov). The research on the 
influence of choice and implementation of the coping strategies of gender, age, cultural and professional characteristics of the individual was conducted as well (T.Y. Argentova, T.Yu. Bilygeldieva, J. Birkirer, F. Blanhard-Fields, A.M. Bogomolov, V.M. Voinenko, V. Klivier, M.A. Kotikundefined, B.F.Lomov, G. Sek, N.O. Syrota, L. Sulsk, G. Tome, etc.).

When we talk about coping with stressful situations by student youth effectively, we mean the implementation of the potential to overcome stressful events, which is reflected in the choice of successful or unsuccessful adaptive behavior strategies, and the level of development and repertoire of adaptation mechanisms are of great importance both for the level of human functioning and for preserving his mental well-being. In addition, the process and the result of overcoming stress depend not only on the size of the resource potential of the individual, but on its confidence in its ability to realize it, as well as the willingness to work on it.

According to the results of scientific research made by D.O. Leontiev, the phenomenology of personal potential fully reflects the concept of hardiness, because it is a mental quality, which combines the power of one's will, freedom, internality, active and meaningful attitude to the world [7, p. 3].

The study of hardiness is an important area of socio-psychological research because the question of the quality of human life, one's satisfaction with oneself, one's learning, work, and family is becoming more and timelier. Attention is focused on the study of key prerequisites that allow you to maintain effective interaction with meaningful people, to succeed in life, to be happy even in the presence of unfavorable external circumstances. Trying to gain stability and security in extreme living conditions, a person, based on internal and external resources, will find an individual way of effective life balancing. At certain periods of life, it may be more effective to take patiently all the difficulties and hardship, or to maximize mobilization and activity.

I. Solkova and P. Tomanek substantiated the influence of hardiness on self-efficacy of a person -its sense of its own competence, which contributes to increasing the ability to withstand various stressors [3, p. 390]. From the point of S. Siddiki and K. Hassan, a life-sustaining person tends to perceive the difficult circumstances as a challenge and readily accepts it as a call to act. And in a situation of personal choice, hardiness is a factor that stimulates the search for new, non-standard solutions, reduces the fear of uncertainty, and determines the ability for mature and complex forms of self-regulation [10, p. 226]. 
Thus, hardiness is an integral quality that combines meaningful goals and values for an individual, self-adaptation, and stylistic characteristics of behavior, deterministic attitudes and beliefs about the world, social environment and its place in it. Accordingly, this mental quality is a complex personal formation, which includes three relatively autonomous attitudes: commitment, control, and acceptance of risk [7, p. 5]. "Commitment" - the conviction of a person that others value and respect him or her, confidence in his or her own powers, the correctness and usefulness of the performed activity, the social significance of its results. It is the ability to perceive the surrounding reality and life events as a source of vivid impressions, interesting facts and priceless experiences, the desire to be always at the streaming of events and expand the range of contacts. Underdeveloped «commitment» generates alienation from others and rejection of oneself, «falling out» from the context of life events.

«Control» - the attitude not to spare the effort and time on the way to hard-reaching goals, without doubting the correctness of the decisions and their ability to implement them; the conviction that everyone chooses his own path and is responsible for his own life, that all made efforts are justified, even if they are not crowned with absolute success, the defeat also requires revenge on the person. Poorly developed «control» provokes a feeling of helplessness and worthlessness, fear of the future and «lowering of hands».

«Challenge»-the conviction that life experience is the source of priceless knowledge, and failures are the motive for personal growth. This is the ability to see positive moments in any situation; mindset of «live to the full», «chase the dream», the willingness to take risks, even when success is questionable, disregard for opportunism and consumer lifestyle. Undeveloped ability to «risk taking» inhibits the growth and expression of inner potential, blocks the self-development activity and initiative of a person, causes excessive anxiety in situations of uncertainty, conservatism and rigidity, domination of motivation to avoid failure over the desire to succeed.

The hardiness of juvenile persons is not a universal or fixed personal characteristic. Its meaning varies depending on the type of stress, its context, as well as the socio-psychological conditions of life. Today, a modern student can observe the lack of a clear, holistic model of his own lifestyle, he has poor developed, or lack of practical skills on the threshold of an adult life, inadequate self-regulation skills and organization of his own activities in the life of the time space. 
While investigating the relationship between hardiness, coping strategies and psychological well-being V.O. Olefir found out that the tightness and direction of correlation between the scales of hardiness, coping strategies and psychological well-being scales suggest that hardiness, indirectly, affects psychological well-beingthrough the choice of coping strategies, that is, the regulatory impact of hardiness on the psychological well-being of the individual is mediated by the coping- strategies [8, p. 170].

According to N.M. Volobueva, students with high hardiness level are actively «involved» in learning, aware of their leading role and responsibility in the process of education, are able to learn experience and make conclusions from difficult educational situations, always trying to think about strategies to achieve the goals, but act flexibly, quickly adjusting action plans; have an adequate self-esteem and are emotionally balanced, seek self-development on the basis of self-knowledge and they are focused on the full realization of their potential opportunities [2, p. 14]. Thus, as evidence of the results of today's researchconvinces us, the developed hardiness of the student's personality is the key to his successful self-realization and the ability to overcome stress.

Having investigated stress relief in a variety of stressful situations, S. Folkman, showed that in general, the overcoming are «more likely to be varied than stable», but some strategies to overcome showed relative stability regardless of the situation. For example, it turned out that the strategy of «positive revaluation» is most closely related to personal factors, while the focus on the strategy of «confrontation», «search for social support» and «systematic solution of the problem» depended to a large extent on the situation itself [11, p. 30]. R. Lazarus argues that people are more likely to use more active ways to overcome stress (planning, suppression of competing types of activity) in controlled situations than in situations that are not subject to control and influence [11, p. 46]. In contrast to the position mentioned above, J. Amirkhan believed that the individual's choice of certain coping strategies was a rather stable characteristic throughout his lifetime, which depended heavily on the type of stressor. He marked them as basic strategies of human behavior and grouped into three groups: 1) solution of the problem (adaptive); 2) search for social support (adaptive); 3 ) avoiding the problem (non-adaptive) [9, p. 1169]. Despite the fact that these fundamental strategies do not exhaust all the coping capabilities of the individual, the author emphasizes that they correspond to the main human 
reactions to the threat, thus characterizing the general tendencies of coping behavior. In general, most researchers sad here to a unified classification of ways to overcome stress: 1) coping strategies affected the situation; 2) cognitive strategies aimed at re-evaluating the situation; 3) effort store move emotional stress.

It must be kept in mind that a person uses not only one type of coping, but a whole set of techniques and methods, both problem-oriented and emotionally orientated coping. The choice of which types of coping strategies will be used in stressful situations is largely dependent on the cognitive assessment of the stressful situation in which a person has fallen.

R. Lazarus proposed two forms of assessment of the situation - primary and secondary. In the initial assessment, a person evaluates his resources, in other words, answers the following question - «What do I have to overcome in this situation?" The answer to this question contributes to the quality of his emotional reactions and their intensity. In the secondary assessment, a person evaluates his possible actions, and predicts the appropriate actions of the environment. In other words, he asks questions such as «What can I do? What are my strategies to overcome? And how will the environment respond to my actions? » The answer affects the type of coping strategy that will be selected to manage a stressful situation [11, p. 67].

The style of overcoming is actively formed at a young age, at the initial stage of becoming an adult. They are tested in practice and selected as the most appropriate and effective ways to solve problems. With age, the repertoire of overcoming expands, and in the future, the person more unknowingly (automatically) uses the elaborate repertoire of behavior, formed in a stable system of views and approaches to certain phenomena. The ability to evaluate the situation objectively and one's own opportunities to influence is developing, that becomes a key factor in choosing an effective way to overcome it.

However, the concept of «hardiness» is not identical to the notion of coping strategies, or strategies for mastering life difficulties. From Lazarus and Folkman's point of view, these strategies are aimed at overcoming life difficulties: a strategy of confrontation, a distancing strategy, a selfcontrol strategy, a strategy for search of social support, a strategy for taking responsibility, a strategy for avoiding, a strategy for a planned problem solution and a revaluation strategy [11, p. 61].

The differences between hardiness and coping strategies consist in the following: 
- coping strategies are methods, action algorithms, customary and traditional for a person, whereas «hardiness» is a personality trait, mindset set on survival;

- coping strategies can take both productive and unproductive forms, even lead to regression, and «hardiness» is a personality trait that allows you to cope with distress effectively and always in the direction of personal growth.

This is due to existing approaches to the study of coping strategies. On the one hand, the choice and implementation of coping strategies is a psychological factor that affects the experience of stress, the effectiveness of activity, health and illness. In this case, coping strategies are understood and investigated as full independent variables. On the other hand, copings, as patterns of behavior, are themselves a consequence of other psychological factors and can be considered as dependent variables. Active change in the stress situation, its positive revaluation is evidence of successful coping with stress. Hardiness affects the choice of coping strategies and only through them - indirectly - on the effectiveness of activities, health and illness [12, p. 87].

\section{Research methodology}

There werestudiedthe students from the universities of Kharkiv and Bakhmut of the Donetsk region in the number of 124 people (71 were females, 53 were males, but the gender aspect was not taken into account).

Procedure. By using S. Muddy's Resistance Test in the adaptation of D.A. Leontiev, O.I. Rasskazova [7, p. 30] the students were divided into three groups: students with low level of survival (27 persons), students with average level of survival (58 persons), and students with high level of survival (39 people).

Next, immediately before the exam or the grade, participants were asked to respond to the battery of the Coping Test by R. Lazarus and S. Folkman, adapted by T.L. Kryukova, E.V. Kuftyak [4, p. 6]. The same test was conducted with the studied students and in the course of ordinary educational work to compare the shift of indicators.

There were used non-parametric methods to process the results-Student's T-criterion, N-Criterion of Kraskele-Wallis and W-Wilcoxon Criteria, as well as correlation analysis. The calculations were performed in the STATISTICA 7.0 system. 


\section{Analysis and discussion of results}

In the textbook of D.O. Leontiev and O. Rasskazova [7, p. 30] in the section reflecting the results of testing the hardiness test by $\mathrm{S}$. Maddi in the Russian-speaking sample, there is no any statistical data that allows the studiedpeople to be grouped by the levels of hardiness. Therefore, while determining the boundary values, the percentile scale was used. All students with results located to the left of 33.33 percentiles were classified as lowviability groups, while the studied ones, whose results turned out to be 66.66 percentile, were considered high-endurance groups. The results of a group with an average level of viability are distributed between 33.33 and 66.66 percentiles. Thus, the levels of data values have been defined, which made it possible to classify the studiedstudents to a group with high, medium and low indicators of hardiness.

In the processing of the results of the Coping Test by R. Lazarus and S. Folkman adapted by T.L. Kryukova and E.V. Kuftyak, some differences in the coping strategies during the session were detected, depending on the level of hardiness (Figure 1).

Stress effects are processed by a person on the basis of hardiness, and it is a catalyst for behavior, which allows you to transform the negative experience into new possibilities. It is this trait that is the basis of an open

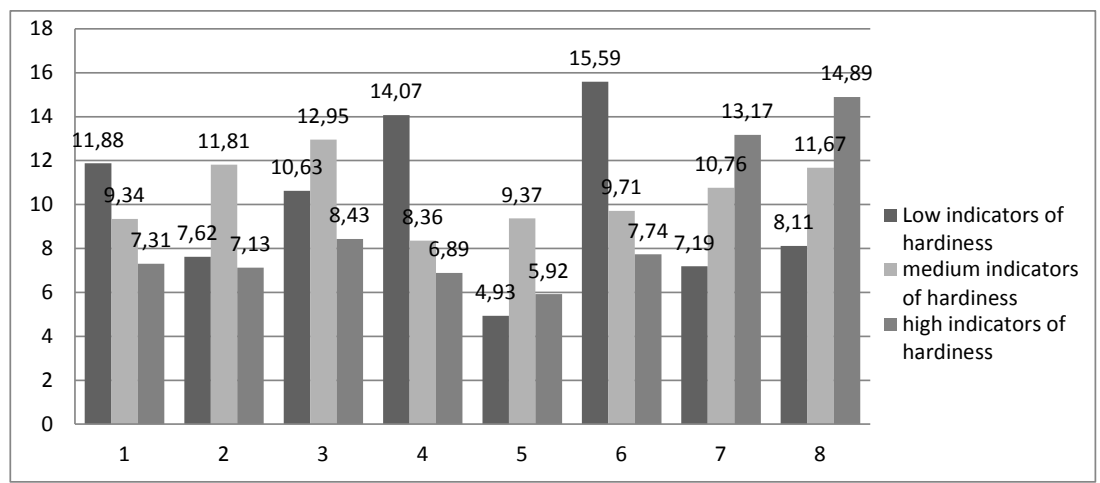

Figure 1. Results of the diagnosis of coping strategies depending on the level of students' hardiness during the sessional period

1 - confrontation, 2 - distancing, 3 - self-control, 4 - search for social support, 5 acceptance of responsibility, 6 - avoidance, 7 - planning problem solution, 8 - positive revaluation 
and energetic confrontation with stressful events and crises.Overcoming problems can occur in two ways - either active or passive. According to the data obtained from the study, we see that for types of coping strategies, such as confrontation $(11,88 \pm 2,61)$, social support searches $(14,07 \pm 1,85)$ and avoidance $(15,59 \pm 1,04)$, and they have the lowest rates on acceptance of responsibility scales $(4,93 \pm 0,82)$, planning problem-solving $(7,19 \pm 0,48)$ and positive revaluation $(8,11 \pm 2,51)$. Stress situations, as a rule, impose requirements beyond the limits of the person's ability to deal with them, even if there are the necessary resources for it. As a result, the person shows a real inability to solve the problem, perceives one's own inability to cope with the requirements of a stressful situation. This may indicate that in a situation of stress, the solution to a problem occurs due to not always focused behavior al activity or the implementation of certain actions, but by increasing the activity, often impulsive, in consistent and chaotic in order to try to affect the situation somehow.In external behavior, this will manifest itself in the desire to «climb into a bottle», «bump into a conflict», quarrel with someone, resent and deal with others in an aggressive way, defend their position, argue with the goal to «achieve justice» and maintain their self-esteem. It is also possible to involve external (social) resources, to seek information, emotional and effective support, attention, advice, compassion, concrete effective help, active information gathering in order to overcome uncertainty, perceive someone else's experience, and constantly speak out the situation with others in order to weaken emotional tension. There is a possibility of denial of the problem, fantasy, anxiety and emotional stress on the background of keeping hope for a positive conclusion of the situation and other infantile forms of behavior in stressful situations.

Students with a medium level of hardiness have the highest rates for stress management strategies during the session: distancing $(11,81 \pm 1,61)$, selfcontrol $(12,95 \pm 2,07)$, and acceptance $(9,37 \pm 0,83)$. They seek to overcome the negative experiences associated with the problem due to subjective decrease in its significance and the degree of emotional involvement in it, using the intellectual methods of rationalization, switching attention, removal, humor, depreciation, etc.Unlike the mechanisms of psychological defense, «negation» and «rationalization,» these cognitive efforts are conscious strategies for reducing internal stress, but we cannot deny the fact that they are closely related to the unconscious mechanisms of stress management (or are based on them). Often they can purposefully suppress and restrain 
emotions, minimize their influence on the perception of the situation and the choice of a strategy of behavior, control, strive for self-control.But on the other hand, for these students, recognition of their role in the emergence of a problem and responsibility for its decision is one of the main characteristic. It should be said that this strategy is not always a good way to get out of a difficult situation, the more so by solving problems; the expressiveness of this strategy in behavior can lead to unjustified self-criticism and self-denial, feelings of guilt and chronic dissatisfaction with oneself.

The data presented in Figure 1 show that in the stress situation for adolescents with a high level of hardiness the planning of problem solving $(13,17 \pm 0,48)$ and positive revaluation $(14,89 \pm 2,91)$ are typical; they also have the lowest rates among all groups for such coping strategies to overcome the shock as a confrontation $(7,31 \pm 3,31)$, distancing $(7,13 \pm 1,10)$, self-control $(8,43 \pm 1,86)$, search of social support $(6,89 \pm 0,91)$, avoidance $(7,74 \pm 1,39)$. To plan a solution to the problem is characterized by overcoming the problem through a purposeful analysis of the situation and possible behavior, the development of a strategy for solving the problem, planning their own actions, taking into account objective conditions, past experience and available resources. For a positive revaluation there is inherent rethinking of the problem situation, considering it as an incentive for personal growth; characteristic focus on the philosophical understanding of the problem situation, the inclusion of it in the wider context of the individual's work on self-development. Related to emotions it is observed preserving faith, hope and optimism. In the cognitive field - attempts to analyze the situation, search for what has happened with the focus on the positive aspects; rethinking oneself, their relationships and life values; the focus of attention and the direction of thought to extract conclusions, finding «benefits/profits» from the current situation. However, the content of this strategy is very close to the action of the mechanism of protection «hypercompensation», may be «sublimation». The ratio of personality to change and his ability to use internal resources determines how much a person is able to overcome stress and difficulties. Such a person views life as a way of gaining experience, both positive and negative, for the purpose of his own development. And the desire for simple comfort and safety is seen as impoverishing the life of the individual.

The applied aspect of hardiness is due to the role that this personality plays in the successful confrontation of the individual with stressful 
situations, most of them in professional sphere. Overcoming the unfavorable conditions of its development is one of the specific forms of manifestation of his personal potential. In the study of the researching of the impact of the level of hardiness on students' coping behavior during the session period, the connection between types of stress management and indicators of hardiness was found (Figure 2).

There is a direct correlation with $\mathrm{p}<0,05$ between hardiness and distancing, self-control, acceptance of responsibility, positive revaluation and problem solving planning. There is also an inverse relationship with $\mathrm{p}<-0.05$ between hardiness and confrontation, search for social support and avoidance. Thus, we can argue that high hardiness indicators help students overcome stress, obstacles, and constructively solve complex situations.This suggests that a life-sustaining person is a person who is adaptive enough, accepts and respects others, feels emotional comfort in relation to his life, his activity and interaction with others, the problems that he encounters on a life-course, tends to solve without translating them on others and circumstances. Reduced hardiness leads to the fact that, being in a risk situation, a person overcomes it with negative consequences

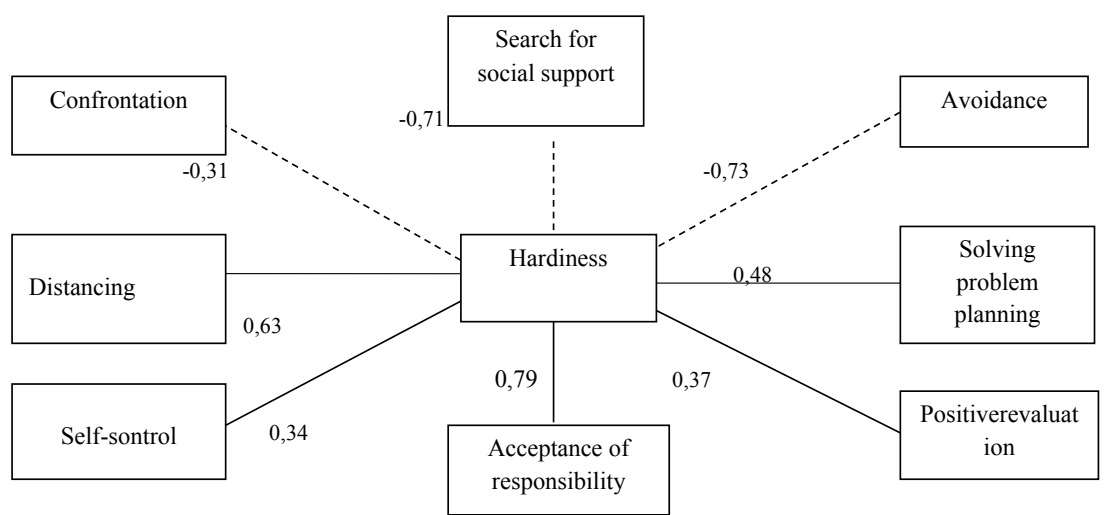

Level of significance $p<0,05$

Level of significancep $<-0,05$

Figure 2. Interconnection of hardiness and coping strategies during a stressful situation 
for mental and physical health, for personal development, for the formed interpersonal relationships.

To overcome stress in difficult life situations, each person uses his or her own copyrighted strategies (behavioral, cognitive and emotional) based on his or her own experience, taking into account the degree of their adaptive capabilities, which are divided into adaptive, partially adaptive and nonadaptive. In the behavioral sphere to adaptive it is accepted to attribute active overcoming and altruism, to a partly adaptive - the search for social support and distraction, to the non-adaptive - compensation with the use of doping agents and departure from reality.In the cognitive sphere, adaptive ones include finding a solution to the problem and adding meaning, to being partially adaptive - avoiding the problem and confusion. In the emotional sphere adaptive refers to emotional concentration, to a partly adaptive - the search for emotional support and emotional discharge, to the non-adaptive the suppression of feelings, feelings of guilt, aggressiveness, obedience. Desired ways to overcome stress are influenced by individual psychological features. The results of the study show that the expressions of these or those methods of responding to complex life situations is put in dependence on the level of hardiness of the individual - the higher the level of hardiness of the individual, the more successful one copes with the difficulties, so he or she uses the adaptive coping strategies. Considering the concept of resource personality, we see that hardiness is the same human internal resource in the process of overcoming the difficulties at different stages of life, which allows you to cope with life's problems optimally.

Since coping is a dynamic process by which individuals in some cases, mainly uses one form of overcoming, for example protective strategy, and others - addresses to strategies to solve the problem by changing the attitude of «personality - environment», we are interested in the question, whether the choice of coping behavior varies depending on the state of stress or rest in students with different levels of hardiness. The participants of the study were asked to respond to the battery of the Coping Test by R. Lazarus and S. Folkman, adapted by T.L. Kryukova, E.V. Kuftyak in the course of the usual educational activity, in the so-called period of rest, this test was conducted with the studied students and just before the exam or the credit. In order to compare the shift of indicators, quantitative analysis was performed using Wilcoxon's W criterion, which allows you to set not only the direction of change, but also its severity. 


\section{Comparison of the coping strategies of students with low level of hardiness before and during the session}

\begin{tabular}{|l|c|c|c|c|c|}
\hline \multirow{2}{*}{} & \multicolumn{2}{|c|}{ Measurement } & $\begin{array}{c}\text { Indexes } \\
\text { T }\end{array}$ & $\begin{array}{c}\text { Value } \\
\text { z-criterion }\end{array}$ & p-level. \\
\cline { 2 - 6 } & I & II & I / II & I / II & I / II \\
\hline Confrontation & $10,77 \pm 0,68$ & $11,88 \pm 2,61$ & 68,00 & 2,34 & 0,02 \\
\hline Distancing & $7,51 \pm 0,51$ & $7,62 \pm 1,07$ & 101 & 0,50 & 0,61 \\
\hline Self-control & $10,44 \pm 0,51$ & $10,63 \pm 1,47$ & 90,50 & 0,54 & 0,59 \\
\hline Searchfor social support & $14,48 \pm 0,50$ & $14,07 \pm 1,85$ & 104 & 1,03 & 0,30 \\
\hline $\begin{array}{l}\text { Acceptance of } \\
\text { responsibility }\end{array}$ & $5,44 \pm 0,70$ & $4,93 \pm 0,82$ & 14 & 2,41 & 0,02 \\
\hline Avoidance & $14,96 \pm 0,94$ & $15,59 \pm 1,04$ & 48 & 2,13 & 0,03 \\
\hline Solving problemsplanning & $7,48 \pm 0,51$ & $7,19 \pm 0,48$ & 33,50 & 1,51 & 0,13 \\
\hline Positive revaluating & $9,18 \pm 0,48$ & $8,11 \pm 2,51$ & 92,50 & 2,11 & 0,04 \\
\hline
\end{tabular}

Ageneral comparative analysis of the results showed statistically significant differences between data reflecting the choice of coping strategies for students with low levels of survival (measurement I) and stress (measure II). Analyzing the data presented in Table 1, we can say that during the rest period of the students, such non-constructive coping strategies as «Confrontation» $(\mathrm{p} \leq 0,05)$, «Avoidance» $(\mathrm{p} \leq 0,05)$ are much more lower, and «Acceptance responsibility» and «Positive revaluation» are higher than in the stress condition $(\mathrm{p} \leq 0,05)$. We see that in the period of rest for these students, strategies aimed at re-evaluating the situation come to the fore, while efforts to remove emotional stress become less relevant.We can assume that in situations of stress, students with a low level of hardinessaddress to mechanisms of protection. Since A. Freud also pointed out that protective mechanisms prevent the disorganization and disintegration of behavior, support the psychological homeostasis of the individual. In her opinion, a set of protective mechanisms characterizes the level of adaptability of the individual. Therefore, in our opinion, the lower the hardiness, the higher the probability of the use of protection mechanisms in situations of conflict, frustration and stress.

Comparing the results of the analysis, we observe the presence of statistically significant differences between the data reflecting the choice of the coping strategy of the students with the medium level of hardiness in a state of rest (measuring I) and in a stressful state (measurement II). 
Comparison of students' coping strategies with average hardiness before and during the session

\begin{tabular}{|l|c|c|c|c|c|}
\hline \multirow{2}{*}{} & \multicolumn{2}{|c|}{ Measurement } & $\begin{array}{c}\text { Indexes } \\
\text { T }\end{array}$ & $\begin{array}{c}\text { Values } \\
\text { z-criterion }\end{array}$ & p-level. \\
\cline { 2 - 6 } & I & II & I / II & I / II & I / II \\
\hline Confrontation & $9,01 \pm 0,88$ & $9,34 \pm 2,32$ & 216,50 & 1,14 & 0,25 \\
\hline Distancing & $11,03 \pm 0,67$ & $11,81 \pm 1,61$ & 180,50 & 3,08 & 0,002 \\
\hline Self-control & $13,53 \pm 0,51$ & $12,95 \pm 2,07$ & 241,00 & 2,27 & 0,02 \\
\hline Search for social support & $8,50 \pm 0,50$ & $8,36 \pm 1,18$ & 347,50 & 1,07 & 0,28 \\
\hline $\begin{array}{l}\text { Acceptance of } \\
\text { responsibility }\end{array}$ & $9,71 \pm 0,84$ & $9,37 \pm 0,83$ & 162,50 & 1,89 & 0,06 \\
\hline Avoidance & $9,50 \pm 1,11$ & $9,71 \pm 1,38$ & 462,50 & 0,85 & 0,39 \\
\hline Solving problem planning & $11,32 \pm 1,04$ & $10,76 \pm 0,46$ & 309,00 & 2,35 & 0,02 \\
\hline Positive revaluating & $11,84 \pm 1,52$ & $11,67 \pm 2,68$ & 591,50 & 0,67 & 0,50 \\
\hline
\end{tabular}

Analyzing the data presented in Table 2, we see that during the rest period of students «Distancing» $(\mathrm{p} \leq 0,05)$ - strategies aimed at removing emotional stress, strategies for emotional exclusion, which allow not to be included in any complex or unpleasant situations, especially if the possibilities for their change (decisions) are small) are significantly lower than and also we see the higher level of "Self-control" $(p \leq 0,05)$ and «Planning problem solving» $(\mathrm{p} \leq 0,05)$ - cognitive strategies, aimed at re-evaluating the situation; conscious efforts to preserve self-control, confidence and optimism, activating mental activity, increasing attention to received information, attentiveness and caution, thinking over their words and actions, alertness to external signals in the stressful state.

In the study of the choice of a coping strategy for students with a high level of hardiness in a state of rest (measuring I) and in a stressful state (measurement II), statistically significant differences were found (Table 3): in the state of rest, the indicators of «Self-control» $(p \leq 0,05)$, «Search for social support» $(\mathrm{p} \leq 0,01)$ and «Acceptance of responsibility» $(\mathrm{p} \leq 0,05)$ are significantly increased.

Students with a high level of hardiness in a state of rest are more focused on active interaction, communication with other people, emotional involvement in the situation, the need for adoption; active collection of information in order to overcome uncertainty, perception of someone else's experience. 
Comparison of the coping strategies of students with high level of hardiness before and during the session

\begin{tabular}{|l|c|c|c|c|c|}
\hline \multirow{2}{*}{} & \multicolumn{2}{|c|}{ Measurement } & $\begin{array}{c}\text { Indexes } \\
\text { T }\end{array}$ & $\begin{array}{c}\text { Values } \\
\text { z-criterion }\end{array}$ & p-level. \\
\cline { 2 - 6 } & I & II & I / II & I / II & I / II \\
\hline Confrontation & $6,97 \pm 0,70$ & $7,31 \pm 3,31$ & 297,00 & 0,29 & 0,77 \\
\hline Distancing & $6,79 \pm 1,39$ & $7,13 \pm 1,10$ & 205,00 & 1,10 & 0,27 \\
\hline Self-control & $9,02 \pm 2,40$ & $8,43 \pm 1,86$ & 157,00 & 2,20 & 0,03 \\
\hline Search for social support & $8,17 \pm 1,89$ & $6,89 \pm 0,91$ & 184,00 & 2,87 & 0,01 \\
\hline $\begin{array}{l}\text { Acceptance of } \\
\text { responsibility }\end{array}$ & $6,35 \pm 0,98$ & $5,92 \pm 1,13$ & 102,50 & 2,07 & 0,03 \\
\hline Avoidance & $7,33 \pm 1,03$ & $7,74 \pm 1,39$ & 122,00 & 1,35 & 0,17 \\
\hline Solving problems planning & $13,74 \pm 1,71$ & $13,17 \pm 0,48$ & 212,00 & 0,97 & 0,33 \\
\hline Positive revaluating & $15,56 \pm 1,12$ & $14,89 \pm 2,91$ & 274,50 & 1,39 & 0,16 \\
\hline
\end{tabular}

\section{Conclusions}

Most scholars see overcoming as ever-changing cognitive and behavioral efforts and focusing on managing specific external and/or internal requirements that are judged from the point of view of the suitability of the individual's resources. To overcome a difficult life situation, a person needs to use all his potential. The probability of developing psychological stress depends on the personality characteristics that determine the degree of resistance to stress. Similar features that increase the resources of confrontation with stressful situations are defined as a sense of coherence, «stress tolerance» or "personal endurance», which is understood as the potential ability to overcome difficulties in an active way. Personality resources largely determine the ability to build an integrated behavior, which allows, even in frustration, mental tension to maintain the stability of the chosen line of conduct, proportionally take into account their own needs and requirements of the environment, correlate immediate results and set aside effects these or those deeds. Concept S. Kobasa and S.R. Maddi considers personality, personality's traits and overcoming as «hardiness» or «hardness, endurance» of personality. The firmness or strength of the spirit (will) is the tendency of the individual to perceive the stressors as a «challenge» as an incentive for personal development and willingness to withstand them. This concept is a resource of stress resistance. 
Our research has shown that for students with low levels of hardiness in rest, typical strategies are aimed at re-evaluating the situation, and coping is focused on the problem, while in a situation of direct stress - a coping is aimed at removing emotional stress. We can assume that in situations of stress, students with a low level of hardinessuse mechanisms of protection. If in the repertoire of coping behavior of the person active problem-solving strategiesare little used, the level of tension psychological protection is more manifested.

Students with high indicators of hardiness prefer adaptive variants of cognitive, behavioral and emotional coping strategies of behavior in a situation of rest, and in a stressful situation. They are more likely to choose ways to overcome the situation and cognitive strategies aimed at re-evaluating the situation. Selected coping strategies in a situation of rest and stress are not diametrically opposed, as for students with low levels of hardiness - they also belong to one group of strategies. High indicators of individual hardiness are negatively related to the choice of emotional coping strategies.

For students with a high and medium level of hardiness, such adaptive coping strategies as self-control, planning of problem solving, positive revaluating of the situation, search for social support, and acceptance of responsibility are expressed to a greater degree. At that time, as for those with a low level, the more intrusive are: confrontation, distance, avoidance.

Problem-oriented coping involves individual attempts to improve the «human-environment» relationship by changing the cognitive assessment of the current situation. For example, by searching for information about what to do and how to do it, or by keeping yourself away from impulsive or hasty actions. Emotion-oriented coping involves thoughts and actions that aim to reduce the physical or psychological effects of stress. These thoughts or actions give a sense of relief, but are not aimed at eliminating a threatening situation, but simply give a person a better feeling. An example of emotionally-oriented coping is: avoiding a problem situation, denying a situation, imaginary or behavioral distancing, humor to relieve symptoms of stress.

However, no one can deny the fact that the majority of respondents do not use the chosen strategies in real life, as they consider the strategies to be the most desirable behaviors in difficult life situations. In other words, we have identified a socially acceptable and approved stereotype of a person's 
struggle with troubles - this is an analysis of the situation, the collection of information and careful reflection on the actions of the stressor, the development of strategies for dealing with it (or prevention).

While studying the correlation between the level of hardiness and the students' coping behavior in the sessional period, the influence of the level of survival on the strategy of overcoming was found. There is a direct link between hardiness and distancing, self-control, acceptance responsibility, positive revaluation and problem solving planning, as well as a return between hardiness and confrontation, search for social support and avoidance. High levels of hardiness help students overcome stress, obstacles, and solve complex situations constructively.

The results of empirical research broaden the idea of the peculiarities of hardiness and coping strategies of students and confirm the significance and impact of the level of hardiness on the choice of behavior to overcome stress.

\section{References:}

1. Babatina S.I. (2016). Vplyv zhyttyestiykosti na osobystisnyy rozvytok v students'komu vitsi [Influence of viability on personal development in student's age]. Proceedings of the Praktychna pedahohika ta psykholohiya: metody i tekhnolohiyi (Ukraine, Zaporozhye, July 1-2, 2016), Zaporozhye: Classical private university, pp. 119-123.

2. Volobueva N.M. (2012). Psikhologicheskaya kul'tura kak usloviye razvitiya zhiznestoykosti studentov [Psychological culture as a condition for the development of students' resilience] (PhD Thesis), Belgorod: Belgorod State National Research University.

3. Kireeva M.V. (2012). Vedushchiye koping-strategii studentov s razlichnym urovnem stressoustoychivosti [Leading coping strategies for students with varying levels of resistance to stress]. Scientific statements of BelSU, vol. 13, no. 6(125), pp. 229-233.

4. Kryukova T.L., Kuftyak E.V. (2007). Oprosnik sposobov sovladaniya (adaptatsiya metodiki WCQ) [The coping survey questionnaire (adaptation of WCQ)]. Journal of practical psychologist, no. 3, pp. 93-112.

5. Kuznetsova L.M. (2014). Zhyttyestiykist' yak faktor uspishnoyi samorealizatsiyi suchasnoyi students'koyi molodi [Viability as a factor in the successful self-realization of modern student youth]. Bulletin of the Chernigiv National Pedagogical University T. Shevchenko, no. 121, pp. 182-187.

6. Larina T.O. (2012). Zhyttyestiykist' yak peredumova postanovky zhyttyevykh zavdan' [Viability as a precondition for setting life's tasks]. Yak buduvaty vlasne maybutnye: zhyttyevi zavdannya osobystosti [How to build your own future: the vital tasks of the individual]. Kiev: National acad. ped Sciences of Ukraine, Institute of Social and Political Psychology, pp. 287-322. 
7. Leontiev D.A., Rasskazova E.I. (2006). Test zhiznestoykosti [Resilience test]. Moscow: Meaning. (in Russian)

8. Olefir V.O. (2011). Vzayemozv'yazok zhyttyestiykosti, kopinh - stratehiy ta psykholohichnoho blahopoluchchya [Interconnection of viability, coping strategies and psychological well-being]. Herald of the Kharkov National University. The series «Psychology», no. 981, pp. 168-172.

9. Amirkhan J.H. (1990). Factor analytically drive measure of cooing: the strategy indicator. J. of Personality and Social Psychology, vol. 59, pp. 1066-1074.

10. Hardie E., Critchley G., Morris Z. (2006). Self-coping complexity: role of self-construal in relational, individual and collective coping styles and health outcomes. Asian Journal of Social Psychology, vol. 9, pp. 224- 235.

11. Lazarus R., Folkman S. (1984). Stress, appraisal and coping. N.Y.: Springer.

12. Maddi S. (1999). The Personality Construct of Hardiness: Effects on Experiencing, Coping and Strain Consulting Psychology. Journal Practice and Research, vol. 51, no. 2, pp. 83-94.

13. Solcova I., Tomanek P. (1994). Daily stress coping strategies: An effect of Hardiness. Studia Psychologica, vol. 36(5), pp. 390-392. 